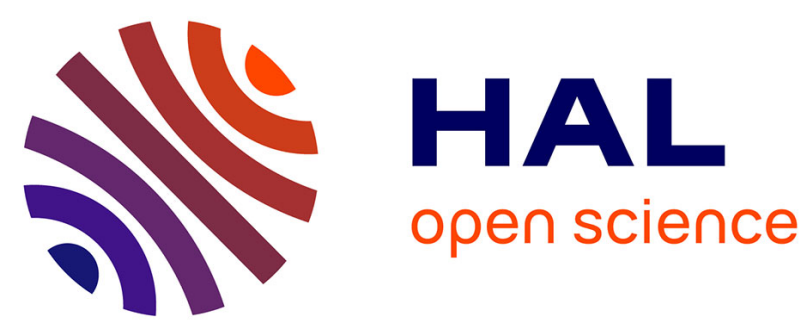

\title{
Experimental and Theoretical Study of Multiscale Damage-Failure Transition in Very High Cycle Fatigue
}

V.I. Betekhtin, A.G. Kadomtsev, M.V. Narykova, M.V Bannikov, S.G. Abaimov, I. S. Akhatov, Thierry Palin-Luc, O.B. Naimark

\section{- To cite this version:}

V.I. Betekhtin, A.G. Kadomtsev, M.V. Narykova, M.V Bannikov, S.G. Abaimov, et al.. Experimental and Theoretical Study of Multiscale Damage-Failure Transition in Very High Cycle Fatigue. Physical Mesomechanics, 2017, 20 (1), pp.78-89. 10.1134/S1029959917010076 . hal-01593831

\section{HAL Id: hal-01593831 \\ https://hal.science/hal-01593831}

Submitted on 26 Sep 2017

HAL is a multi-disciplinary open access archive for the deposit and dissemination of scientific research documents, whether they are published or not. The documents may come from teaching and research institutions in France or abroad, or from public or private research centers.
L'archive ouverte pluridisciplinaire HAL, est destinée au dépôt et à la diffusion de documents scientifiques de niveau recherche, publiés ou non, émanant des établissements d'enseignement et de recherche français ou étrangers, des laboratoires publics ou privés. 


\title{
Experimental and Theoretical Study of Multiscale Damage-Failure Transition in Very High Cycle Fatigue
}

\author{
V. I. Betekhtin ${ }^{1 *}$, A. G. Kadomtsev ${ }^{1}$, M. V. Narykova ${ }^{1}$, M. V. Bannikov ${ }^{2}$, \\ S. G. Abaimov', I. Sh. Akhatov ${ }^{3}$, T. Palin-Luc ${ }^{4}$, and O. B. Naimark ${ }^{2}$ \\ ${ }^{1}$ Ioffe Institute, Russian Academy of Sciences, St. Petersburg, 194021 Russia \\ ${ }^{2}$ Institute of Continuous Media Mechanics, Ural Branch, Russian Academy of Sciences, Perm, 614013 Russia \\ ${ }^{3}$ Skolkovo Institute of Science and Technology, Moscow, 143026 Russia \\ ${ }^{4}$ Institut de Mécanique et d'Ingénierie de Bordeaux, Talence, 33405 France \\ *e-mail:vkmbetek@mail.ru
}

\begin{abstract}
Multiscale mechanisms of failure of metals (Armco iron, titanium, aluminum) are studied for high cycle and very high cycle fatigue. By correlating with the results of structural studies, a theoretical approach is developed to describe fatigue crack kinetics in damaged material under high cycle and very high cycle fatigue loading conditions. Stages of crack nucleation and propagation are analyzed using the profilometry data from the fracture surface. The scale invariance of fracture surface roughness is established, which allows an explanation of the self-similar nature of fatigue crack kinetics under high cycle and very high cycle fatigue. Variation of elastic-plastic properties of Armco iron under very high cycle fatigue is studied using an acoustic resonance method. It is found that the material density decreases during fatigue damage accumulation, with the minimum of the material density in the bulk of the specimen.
\end{abstract}

DOI: $10.1134 / \mathrm{S} 1029959917010076$

Keywords: fracture, scaling, very high cycle fatigue, fractography, fatigue crack initiation and growth

\section{INTRODUCTION}

High cycle and very high cycle fatigue is the most important fundamental and engineering problem for a variety of applications. Series of accidents caused by the gas turbine engine failure [1,2], along with high costs of service life estimation and potential costs of development of new constructions, stimulated advanced concepts of national research programs for high cycle and very high cycle fatigue [2-11], as being based on new fundamental results of fatigue strength evaluation. The programs aim at developing approaches using basic research findings, modern methods of laboratory modeling, and quantitative analysis of structural changes in order to reveal fracture stages and "criticality" mechanisms in transition to macroscopic fracture. A strong interest in the gigacycle range $\left(10^{9}\right.$ cycles) of fatigue loads is provided by the progress in the creation of new (nano- and submicrostructural) materials with a very high cycle fatigue life and by breakthrough tendencies in technologies requiring such life in aviation motor industry [11].
To distinguish stages of initiation and propagation of fatigue cracks is one of the key problems of fatigue failure [10-13], which is solved using the methodology of investigation of damage kinetics, crack nucleation and propagation as well as by means of experimental technique for registration of specific fracture stages. It was previously noted $[7,10,12]$ that a promising approach to evaluating the very high cycle fatigue life is the consistent description of stages of damage accumulation with regard to its multiscale kinetics until the leader crack appears with the size ensuring the applicability of fracture mechanics approaches. The role of the initiation stage is particularly important for gigacycle loading regimes, which are characterized by the generation of the fracture cite of a "fish-eye" shape in the bulk of the material. The stage of fatigue crack growth in the very high cycle regime may be short as the major part of the fatigue life is accounted for the time of formation of the initiation zone [7-13]. 


\section{SPECIAL FEATURES OF CRACK INITIATION IN THE VERY HIGH CYCLE FATIGUE REGIME}

Fatigue damage is traditionally associated with microplastic deformation $[10,13]$ under cyclic loading that induces various microstructural mechanisms of control of the fatigue life, being dependent on the type and initial structure of the material. For plastic metals, there is a special type of localized fatigue (cyclic) deformation (persistent slip bands), whose development usually initiates cracks in the near-surface zone. Another typical mechanism observed, for example, in fatigue fracture of high-strength steels is the generation of damages (in the form of cracks) in the vicinity of inclusions at low load amplitudes corresponding to very high cycle fatigue. Thus, in contrast to conventional studies of very high cycle fatigue focusing on the crack propagation stage, we pose a fundamental problem of the initiation of a fatigue crack during multiscale processes of damage accumulation associated with various defects (localized plastic shear bands, microcracks, pores). In so doing, a qualitative feature of very high cycle fatigue is the fatigue crack initiation in the bulk of the material [7-10]. This radically alters the formulation of the problem of fatigue life evaluation and implies the development of new methods for studying fracture stages, formation of critical conditions for the transition from disperse to macroscopic fracture, experimental and structural methods of assessment of fracture stages. Mughrabi and Höppel also noted that fracture stages are characterized by the irreversibility effects appearing due to localized shears that govern the fatigue crack initiation [10,13].

\section{FATIGUE CRACK GROWTH}

The study of the crack kinetics is one of the important fundamental problems of the mechanics and physics of fracture, which considers crack propagation in the damaged medium by means of new formulations, being a distinctive feature of fracture under very high cycle fatigue. Based on the experimental data, Paris analyzed dependences of the crack growth rate $\mathrm{d} a / \mathrm{d} N$ on the stress intensity factor $K$ and its range $\Delta K$ and found the power law of crack growth $[6,7]$

$$
\frac{\mathrm{d} a}{\mathrm{~d} N}=C(\Delta K)^{m},
$$

where $C$ and $m$ are the material-dependent constants.

The stress intensity factor range is defined as $\Delta K=$ $K_{\max }-K_{\min }$, where $K_{\max }$ and $K_{\min }$ are the maximum and minimum stress intensity factors under cyclic load- ing. In addition to the Paris kinetics, the existence of the threshold value $\Delta K_{\text {th }}$ is anticipated, under which the crack will not propagate.

Once formed, a crack grows further in the material by certain mechanisms that can be divided into the following three stages. Figure 1 is a kinetic diagram of fatigue fracture [7], which describes the crack growth. Stage 1 is a near-threshold growth of the fatigue crack at the crack rate in the range $10^{-6}-10^{-5} \mathrm{~mm} /$ cycle; stage 2 is a stable growth of the fatigue crack (more than $10^{-5}$ but less than $10^{-3} \mathrm{~mm} /$ cycle); stage 3 is an unstable growth of the fatigue crack at $10^{-3} \mathrm{~mm} /$ cycle or higher. The Paris law describes a linear portion of the kinetic diagram and serves as the "upper bound" for the first stage. At stage 3, the crack growth rate proves to be much higher than that predicted by the Paris equation.

The kinetic diagram is indicative of the two main characteristics of the cyclic crack resistance: the threshold stress intensity factor range $\Delta K_{\text {th }}$, below which a fatigue crack does not grow, and the critical stress intensity factor range $\Delta K_{\mathrm{fc}}$, at which a catastrophic fatigue failure occurs. Fatigue failure in the Paris regime is determined by the applied stress and crack length (and its orientation) [14]. However, for small cracks or low stresses when the crack growth kinetics is significantly affected by the structure and damage of the surrounding

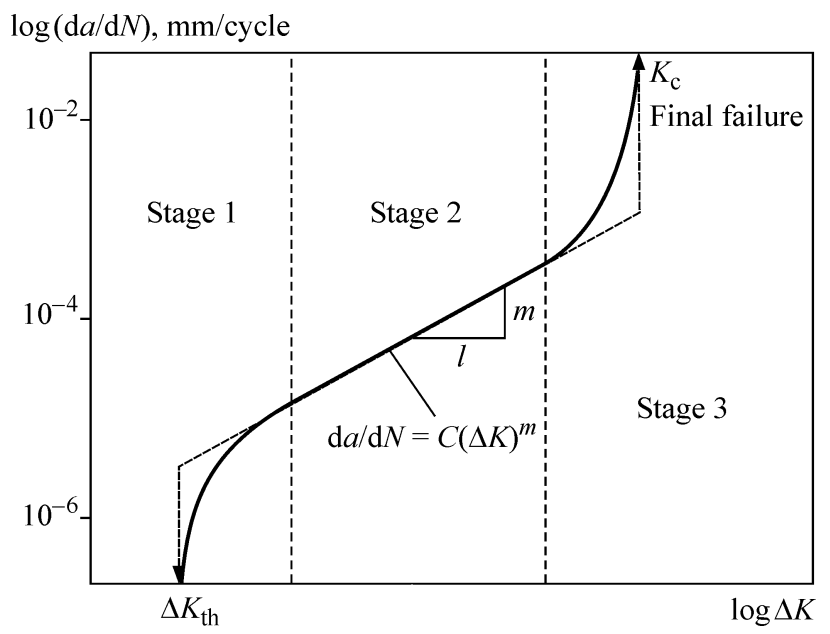

Fig. 1. Kinetic diagram of fatigue fracture, crack growth stages [7]. Stage 1 is strongly influenced by the microstructure, average stress, maximum stress, and environment; stage 2 is strongly influenced by the maximum stresses and weakly influenced by the microstructure, average stress, and environment; stage 3 is strongly influenced by the microstructure, average stress and weakly influenced by the environment. 


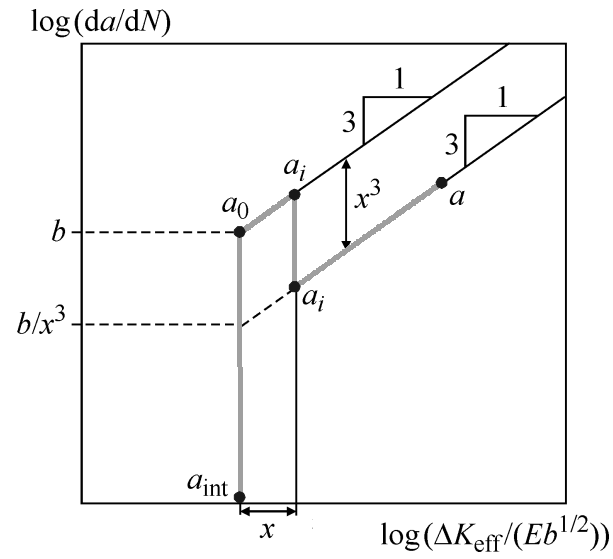

Fig. 2. Schematic diagram of fatigue crack growth depending on the crack size [16].

material, the Paris law cannot be used in its traditional formulation.

To describe the growth kinetics of cracks smaller than "Paris cracks", Miller and Hertzberg $[15,16]$ proposed a phenomenological relation, which, along with the macroscopic characteristics of the stress state at the crack tip $\Delta K$, includes a parameter of the dislocation subsystem, namely, the Burgers vector modulus $b$ (Fig. 2)

$$
\frac{\mathrm{d} a}{\mathrm{~d} N}=b\left(\frac{\Delta K}{E \sqrt{b}}\right)^{\alpha},
$$

where $E$ is Young's modulus. This relation finds wide applications, even for "Paris cracks" due to the introduction of the effective value $\Delta K_{\text {eff }}$.

\section{KINETIC EQUATION OF FATIGUE CRACK GROWTH}

The versatility of kinetics mechanisms determining the relationship between the fatigue crack growth rate and stress intensity factor change $\Delta K$ is the subject of intensive experimental and theoretical research. Powerlaw dependence (1) reflects the self-similar nature of fatigue crack growth due to nonlinear damage accumulation in the vicinity of the crack tip (process zone).

Self-similar features of crack growth were studied by methods of the theory of similarity and dimensions [1719]. The crack growth rate $\mathrm{d} a / \mathrm{d} N$ ( $a$ is the crack length and $N$ is the number of cycles) is dependent on the following parameters:

$$
\frac{\mathrm{d} a}{\mathrm{~d} N}=F\left(\Delta K, E, l_{\mathrm{sc}}, L_{\mathrm{pz}}\right),
$$

where $\Delta K$ is the stress intensity factor range, $E$ is Young's modulus, $l_{\mathrm{sc}}$ is the minimum spatial scale in the vicinity of the crack tip (fracture process zone) on which scale-invariant laws of the fracture surface relief begin to show up, and $L_{\mathrm{pz}}$ is the scale of the fracture process zone at the crack tip. The values of $L_{\mathrm{pz}}$ and $l_{\mathrm{sc}}$ are experimentally determined based on the study of correlation properties using the scale invariant (Hurst exponent) obtained from the analysis of the correlation function of fracture surface profiles. Following the П-theorem [17] in a dimensionless form, function (3) can be represented as

$$
\frac{\mathrm{d} a}{\mathrm{~d} N}=\Phi\left(\frac{\Delta K}{E \sqrt{l_{\mathrm{sc}}}}, \frac{L_{\mathrm{pz}}}{l_{\mathrm{sc}}}\right) .
$$

By evaluating $\Delta K /\left(E \sqrt{l_{\mathrm{sc}}}\right) \ll 1$ and $L_{\mathrm{pz}} / l_{\mathrm{sc}} \gg 1$, we can suggest the intermediate asymptotic nature of crack growth kinetics and write (4) in the form

$$
\frac{\mathrm{d} a}{\mathrm{~d} N}=l_{\mathrm{sc}}\left(\frac{\Delta K}{E \sqrt{l_{\mathrm{sc}}}}\right)^{\alpha}\left(\frac{L_{\mathrm{pz}}}{l_{\mathrm{sc}}}\right)^{\beta},
$$

where $\alpha$ and $\beta$ are the exponents generating the intermediate asymptotic dependence of crack growth kinetics on the dimensionless variables. We introduce the parameter $\Delta K_{\text {eff }}=\Delta K\left(L_{\mathrm{pz}} / l_{\mathrm{sc}}\right)^{\beta / \alpha}$ and write Eq. (5) in the form

$$
\frac{\mathrm{d} a}{\mathrm{~d} N}=l_{\mathrm{sc}}\left(\frac{\Delta K_{\mathrm{eff}}}{E \sqrt{l_{\mathrm{sc}}}}\right)^{\alpha} .
$$

In the limit $l_{\mathrm{sc}} \rightarrow b$ (where $b$ is the Burgers vector modulus), $L_{\mathrm{pz}} \rightarrow l_{\mathrm{sc}}$, and consequently $\Delta K_{\text {eff }} \rightarrow \Delta K$, the derived equation of crack growth kinetics will acquire the form of the Herzberg equation (2) [15].

The scales $L_{\mathrm{pz}}$ and $l_{\mathrm{sc}}$ were previously determined by the profilometry data at the fatigue crack tip for R4 steel [20]. These data presented in logarithmic coordinates in accordance with (6) allow an assessment of the critical scale $l_{\mathrm{sc}}$. The lower limit of the spatial scale $L_{\min }$ is taken as the critical scale $l_{\mathrm{sc}}$ (Fig. 3).

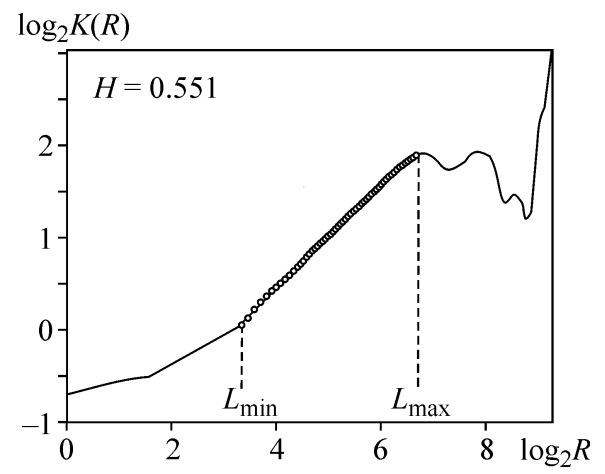

Fig. 3. Typical form of the dependence of $\log _{2} K(R)$ on $\log _{2} R$ of the fracture surface relief. 


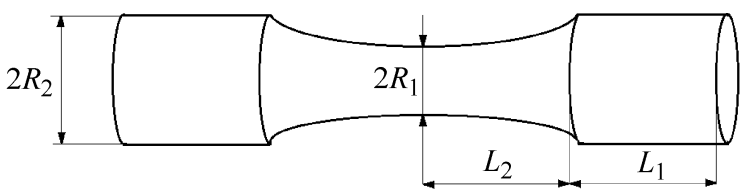

Fig. 4. Geometry of the specimens with the dimensions $L_{1}$, $L_{2}, R_{1}, R_{2}$ chosen to satisfy the resonance condition by formulae described in [7].

\section{FATIGUE TESTING OF TITANIUM AND ITS ALLOYS IN THE HIGH CYCLE AND VERY HIGH CYCLE FATIGUE REGIME}

Tests are performed on cylindrical specimens with the geometry of an hourglass (Fig. 4) made of titanium alloy VT-6 (Ti6A14V) and commercially pure Grade 4 titanium in different microstructural states. In the initial coarse-grained state, the average grain size is $25 \mu \mathrm{m}$; in the ultrafine-grained (submicrocrystalline) state UFG-1, $150-200 \mathrm{~nm}$; in the ultrafine-grained state UFG-2, $200 \mathrm{~nm}$. A grain is refined by equal-channel angular pressing in the following conditions: $T=450^{\circ} \mathrm{C}, 8$ passes, drawing from 14 to $9 \mathrm{~mm}$ at $T=200^{\circ} \mathrm{C}$ for UFG- 1 and $T=450^{\circ} \mathrm{C}$, 4 passes, warm rolling from 12 to $8 \mathrm{~mm}$ at $T=350^{\circ} \mathrm{C}$ for UFG-2.

Transmission electron microscopy reveals that in the UFG-1 state the microstructure is more uniform and grains are equiaxed in both transverse and longitudinal cross sections. In the UFG-2 state, there is a developed metallographic texture in the longitudinal cross section of the bar, which is characterized by elongated grains with the dislocation substructure resulting from rolling after equal-channel angular pressing.

Fatigue tests are carried out on the resonant-type machine (Shimadzu USF-2000) with the cycle asymmetry coefficient $R=-1$ (Fig. 5). The test machine consists of the following main parts: a generator that converts the frequency of $50 \mathrm{~Hz}$ to ultrasonic electric sinusoidal signal with the frequency $20 \mathrm{kHz}$, a piezoelectric transducer that transforms longitudinal ultrasonic waves to the mechanical action of the frequency $20 \mathrm{kHz}$, and an ultrasonic waveguide that generates the maximum amplitude of mechanical stress in the working (middle) part of the specimen. The frequency change by $0.5 \mathrm{kHz}$ during the test corresponds to the appearance of a crack with a characteristic size of about $2 \mathrm{~mm}$.

The test results are shown in Fig. 6 in comparison with the literature data [7] for alloy Ti6Al4V. Fatigue failure of alloy VT- 6 occurs after $10^{9}$ test cycles at the stress

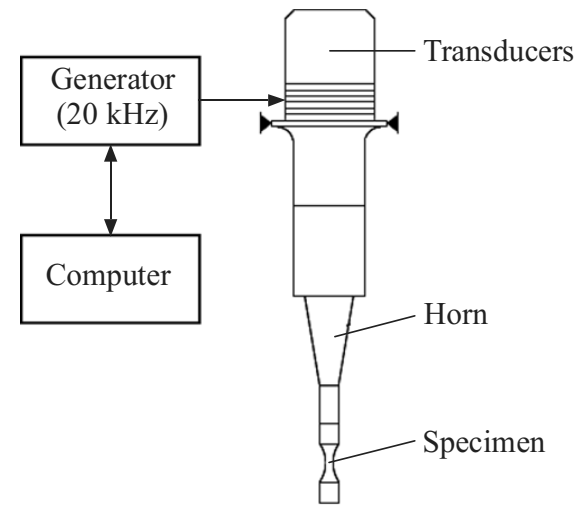

Fig. 5. Experimental setup for very high cycle fatigue tests.

amplitude $495 \mathrm{MPa}$. Grade-4 Ti fails after $10^{9}$ loading cycles at stress amplitudes $275 \mathrm{MPa}$ for the initial state and at 375 and $340 \mathrm{MPa}$ for the UFG-1 and UFG-2 states, respectively. The results of fatigue testing of titanium alloy VT-6 (Ti6Al4V) in the very high cycle loading regime are in good agreement with the data derived by Bathias and Paris [7]. In the very high cycle regime, fatigue characteristics are shown to depend on the material microstructure. In the polycrystalline state of the structure with the grain size $25 \mu \mathrm{m}$, titanium is exceeded in fatigue strength by the submicrocrystalline modification. The two submicrocrystalline states are also different in fatigue properties: Grade-4 Ti in the UFG-1 state with equilibrium grain boundaries exhibits higher fatigue properties as compared to that in the UFG-2 state with the less uniform state of grain boundaries.

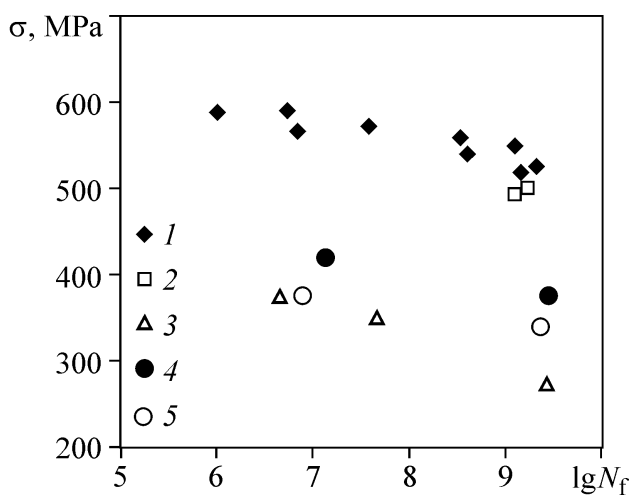

Fig. 6. Test results on very high cycle fatigue: 1 - the fatigue life data for alloy Ti6A14V [7]; 2-alloy VT-6; 3-Grade-4 $\mathrm{Ti}$ in the initial state; 4 - Grade- $4 \mathrm{Ti}$ in the ultrafine-grained state UFG-1; 5-Grade-4 Ti in the ultrafine-grained state UFG-2. 


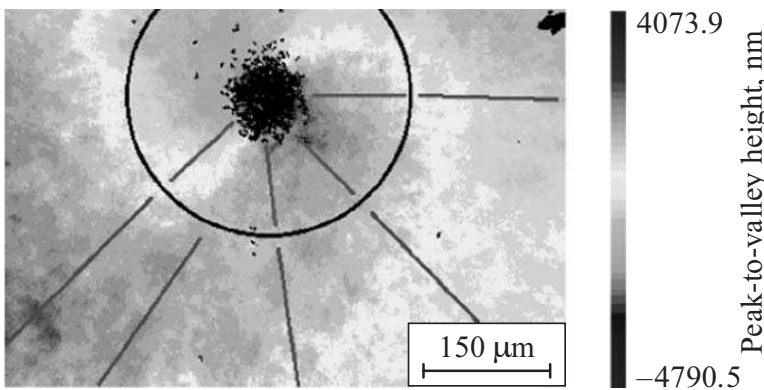

Fig. 7. Images of the fatigue crack nucleus and specific zone of increased roughness around it taken by the New View 5010 interferometer. Solid and dashed lines show the investigated one-dimensional profiles in zones I and II, respectively.

\section{QUANTITATIVE FRACTOGRAPHY OF FRACTURE SURFACES}

Mechanisms of fatigue failure in the very high cycle regime are studied by quantitative fractography based on the data of optical microscopy and high-resolution profilometry of the fracture surface (New View 5010 interferometer-profilometer).

Specimens made of titanium and its alloys with a characteristic fracture ("fish-eye"), whose cite is in the bulk of the material, demonstrate zones with pronounced roughness around the crack nucleus (zone I), which are about $100 \mu \mathrm{m}$ in diameter for pure Grade- 4 titanium and $300 \mu \mathrm{m}$ in diameter for alloy VT-6 (Fig. 7). Zone I is surrounded by zone II, which covers the largest part of the fracture surface and is smoother than zone I.

\subsection{Methods of the Fracture Surface Analysis \\ 6.1.1. Scale kink method}

Methods for evaluating the correlation length are tested with the aid of measurements of roughness profiles in high-strength steel obtained by the New View 5010 interferometer-profilometer (Fig. 8).

The structural scaling parameter is introduced at calculating the correlation function [20-28]

$$
K(R) \equiv \sqrt{\left\langle(h(x+R)-h(x))^{2}\right\rangle},
$$

provided that there are scales $R \ll \xi$ ( $\xi$ is the correlation length) on which the relief reveals correlated fluctuations which are indicative of the power-law dependence

$$
K(R) \propto R^{H},
$$

where $H$ is the relief scaling (surface roughness) index (Hurst exponent). Therefore, the correlation length is determined as the scale, at which the structural scaling parameter begins to deviate from the power-law depen- dence, meaning that the crack behavior is not determined by the material state on scales $R \gg \xi$. The correlation scale can be thus associated with the scale of a zone in the vicinity of the crack tip defining its kinetics.

The proposed approach can be used with sufficient accuracy for long profiles of the fracture surface. However, if the length of the experimental profile is limited, this approach can demonstrate a sufficiently wide scatter of the correlation function values. In addition, oscillations might be responsible for the ambiguous definition of intersection points of the correlation function and power-law dependence (Fig. 9). In accordance with the standard procedure, each of the five intersection points can be taken as the correlation length.

\subsubsection{Method of the first zero point of the correlation function}

An alternative approach to determining the correlation length can be the calculation of the correlation function on two different scales $R \ll \xi$ and $R \gg \xi$. In the first zone the correlation function has a power-law slope, and in the second zone there is a transition to an exponential dependence. The dependence is kinked at the
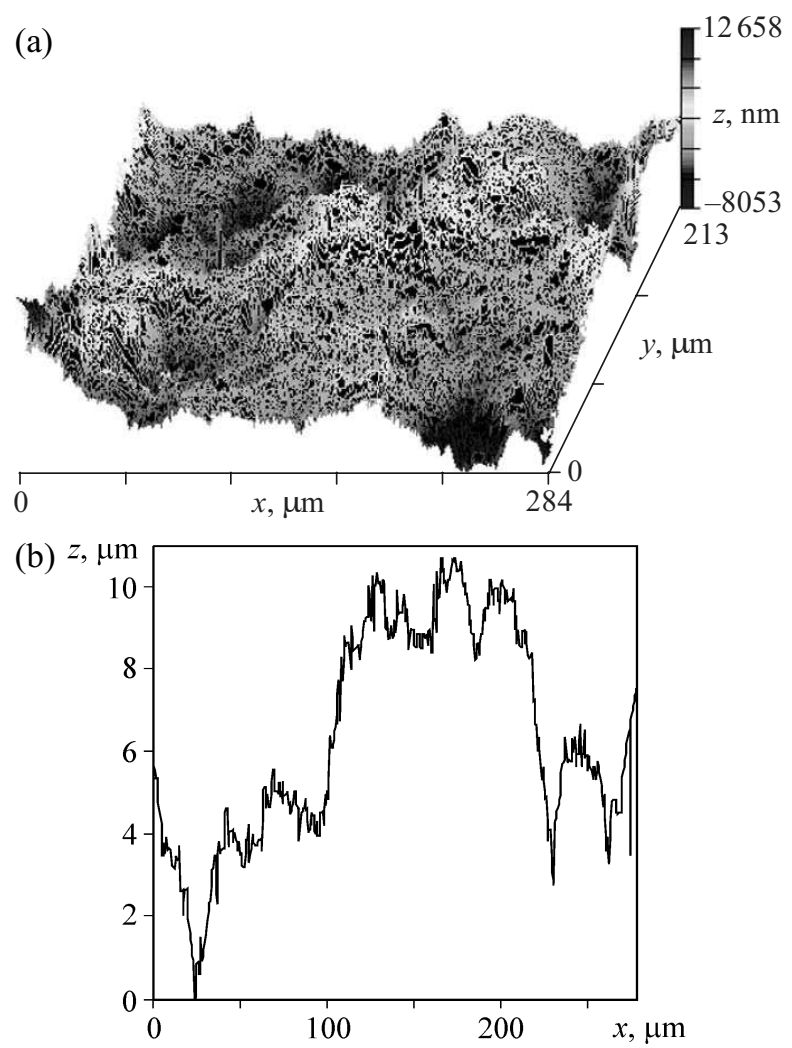

Fig. 8. 3D-image of the fracture surface of steel R5 (a) and the analyzed one-dimensional profile (b). 


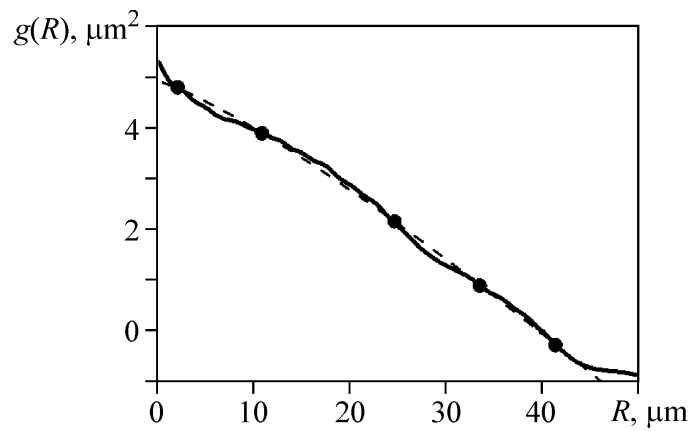

Fig. 9. Oscillations of the correlation function and the assessment of the correlation scales. The solid line is the experimentally obtained correlation function, and the dashed line is the power-law extrapolation. $g(R)=g(0)-K^{2}(R) / 2=K^{2}(\infty) / 2-$ $K^{2}(R) / 2$.

correlation point and the correlation length can be found as the first zero point of the correlation function (Fig. 10a).

\subsubsection{Method of the first zero point of the power-law function}

As Fig. 9 suggests, the scatter strongly affects the calculation results of the correlation length. To eliminate this effect, the correlation length is proposed to be determined by the zero point of the power law built as an extrapolation of the experimental correlation function in the first zone (Fig. 10b).
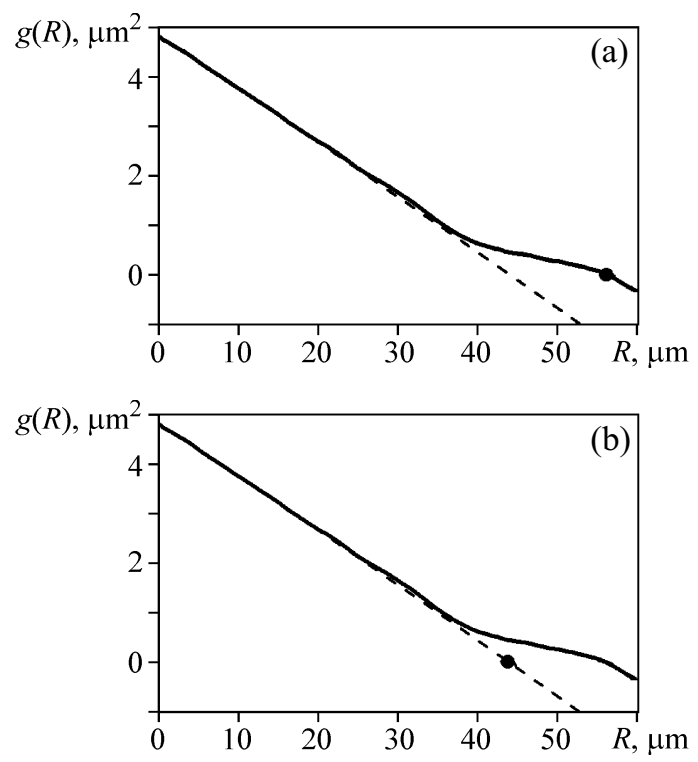

Fig. 10. Calculation of the correlation length using the method of the "first zero point" of the correlation (a) and powerlaw function (b). The solid line is the experimentally obtained correlation function, the dashed line is the power-law extrapolation.
The calculation procedure includes averaging of the correlation function over all profiles of the specimen surface roughness and the subsequent extrapolation by the power-law path (Fig. 11).

\subsection{Analysis of Profiles of the Fracture Surface Roughness}

We selected profiles whose direction corresponded to the fatigue crack propagation (Fig. 12). Two specific zones were found [28], being very different by the roughness relief and consequently by Hurst exponent values (Fig. 12). Zone I $\sim 80-250 \mu \mathrm{m}$ in diameter (depending on the test material) has high roughness in the vicinity of the fracture site and corresponds to the zone of defect accumulation and fatigue crack initiation; zone II, covering the rest of the fracture surface, is smoother than the first one and corresponds to the Paris crack propagation law. These results confirm the crack initiation mechanisms described by Sakai [8].

The correlation function built by profiles including both specific zones has two linear portions with a kink on the scale corresponding to a change in the formation mechanisms of the fracture surface relief while the functions built by profiles within the zones have the only linear portion (Fig. 13).

The analysis of scale-invariant mechanisms shows that the zone around the fracture site is associated with microdamage localization. As cyclic loading proceeds, defects are accumulated and form a fatigue crack of the critical size, starting with which the crack grows by the Paris law. The Hurst exponent is close to values derived by Shanyavsky [2] for fatigue failure of aluminum alloys in the Paris regime.

In Grade-4 titanium specimens in the very high cycle loading regime, the fatigue crack is initiated at a depth of $70-150 \mu \mathrm{m}$ below the surface. A characteristic diffe-

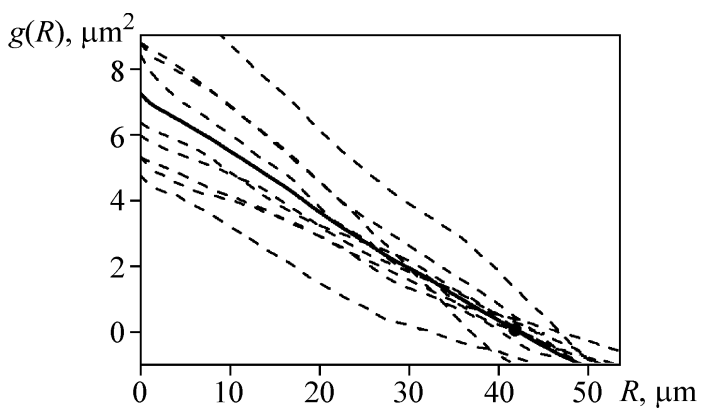

Fig. 11. The method of averaging profiles. Dashed lines are correlation functions constructed for all specimen profiles, the solid line is an average value. 


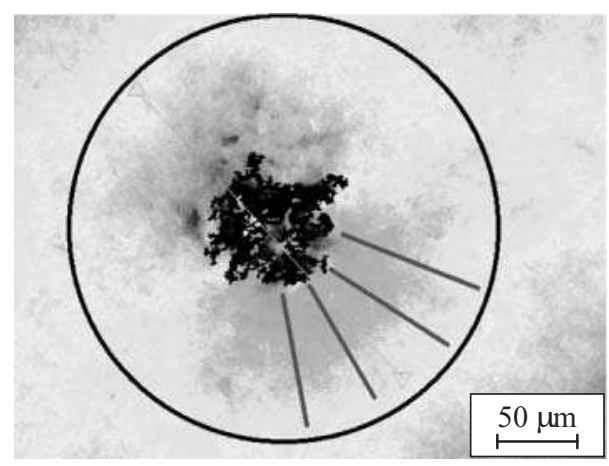

(a)

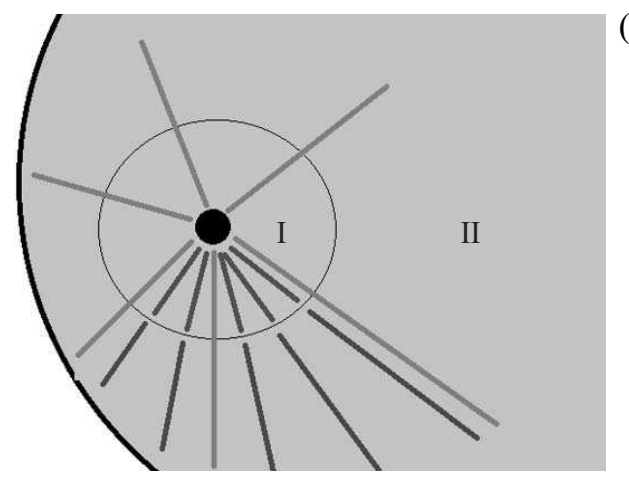

(b)

Fig. 12. Image of the fatigue crack nucleus and specific zone of increased roughness around it taken by the New View 5010 interferometer (a); schematic of the study of the fracture surface of cylindrical specimens in the very high cycle fatigue regime using the New View 5010 interferometer (b). Digits I and II designate crack initiation and growth zones, respectively. Solid lines show the cross section directions of the surface profiles, for which scale invariants are calculated (Hurst exponent).

rence of the fracture surface of such specimens from that of alloy VT-6 is the lack of any zone boundaries in the optical image. However, the height map plotted using the data of the New View 5010 profilometer reveals a characteristic crack initiation zone around the fracture cite, whose roughness differs from the rest zone of crack propagation and whose radius is equal to about $40 \mu \mathrm{m}$.

Fracture surfaces profiles of specimens with the surface initiation of a fatigue crack were also studied on the basis of the profilometrically constructed correlation function. For these profiles, the correlation function has only one slope on the entire fracture surface both near and far from the fracture cite. The value of the linear slope of the correlation function corresponds to the value of the fractal dimension of the crack profile propagating by the Paris law. The defect accumulation zone typical of the subsurface crack initiation is undetected. This point to fundamentally different mechanisms of surface and subsurface fatigue crack nucleation.
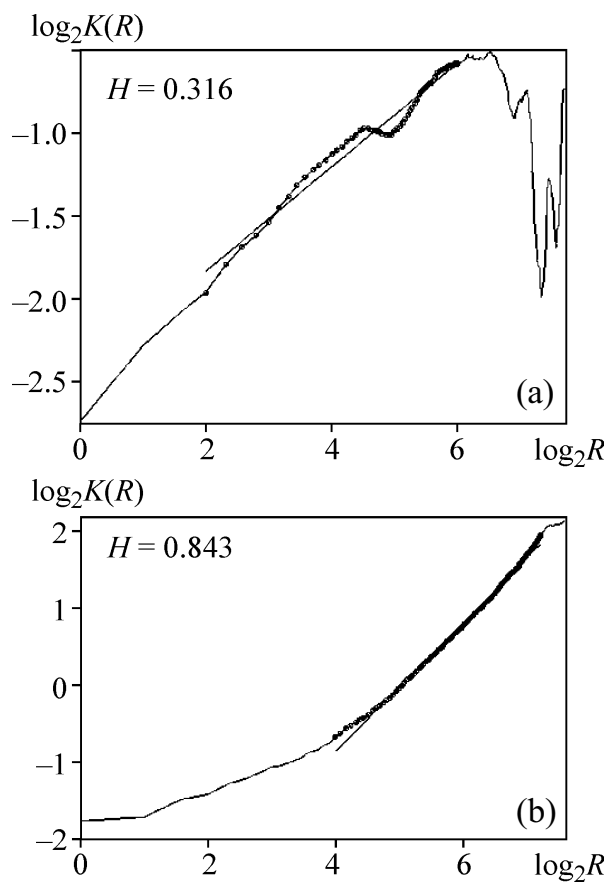

Fig. 13. The correlation function plotted by the one-dimensional profile of the fracture surface of alloy VT- 6 within zones I (a) and II (b).

\section{CHANGES IN ELASTIC-PLASTIC PROPERTIES OF METALS DURING VERY HIGH CYCLE FATIGUE}

To determine changes in elastic-plastic properties during fatigue loading, the specimens are post-test analyzed by the acoustic resonance method with the composite piezoelectric vibrator using longitudinal vibrations on frequencies of about $100 \mathrm{kHz}$. The elastic modulus and amplitude-independent decrement are thereby measured in a wide range of strain amplitudes. Moderate amplitudes are used to retain the dislocation structure of the specimens; the dislocation density remains unchanged after acoustic action [29]. Rods cut from initial specimens measure $30 \mathrm{~mm}$ in length and $d \approx 5 \mathrm{~mm}$ in diameter. The chosen length of the specimens provided the resonance frequency $f$ of longitudinal oscillations of about $100 \mathrm{kHz}$, the elastic modulus is found as $E=4 \rho l^{2} f^{2}$, where $l$ is the length, $\rho$ is the density of the specimens, and $f$ is the vibration frequency. The method used allows an investigation of ultrasound attenuation (internal friction) and inelastic (microplastic) properties. The data on inelastic properties are obtained from the measurement of the elastic modulus $E$ and elastic vibration decrement $\delta$ in a broad amplitude range of vibration strain $\varepsilon$, when at rather large $\varepsilon$ the nonlinear amplitude-dependent dec- 


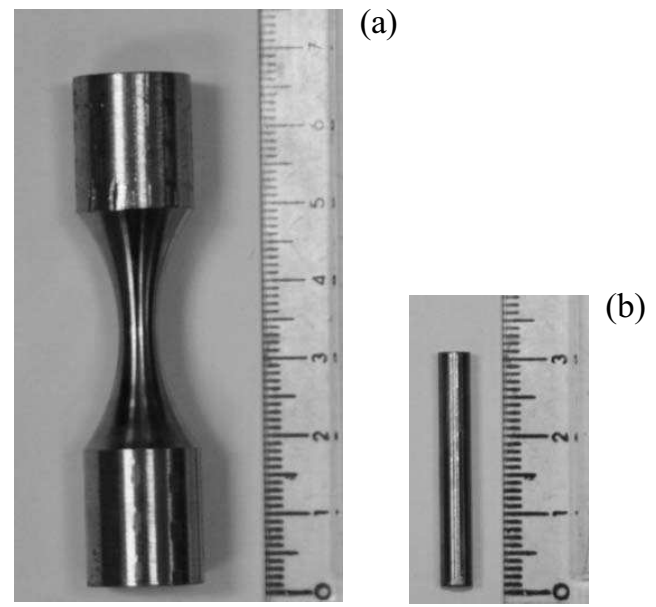

Fig. 14. Appearance of Armco iron specimens as-received (a) and prepared for elastic-plastic investigation (b).

rement $\delta_{h}=\delta-\delta_{i}$ and amplitude-dependent defect of the elastic modulus $(\Delta E / E)_{h}=E-E_{i} / E_{i}$ appear in the specimen material. Here $E_{i}$ and $\delta_{i}$ are the elastic modulus and decrement measured at low amplitudes, where the modulus $E$ and decrement $\delta$ are still independent of $\varepsilon$. Acoustic measurements in a wide amplitude range allow an estimation of microplastic properties of materials in stress-inelastic strain coordinates conventional for mechanical tests where stress amplitudes $\sigma=E \varepsilon$ are ordinates and nonlinear inelastic strains are abscissas $\varepsilon_{d}=\varepsilon(\Delta E / E)_{h}$.

The studies are conducted on Armco iron specimens in the initial state and after a different number of cycles of very high cycle fatigue testing. The following notations are given further for specimens:

specimen no. 1, P0 - initial (without very high cycle fatigue testing),

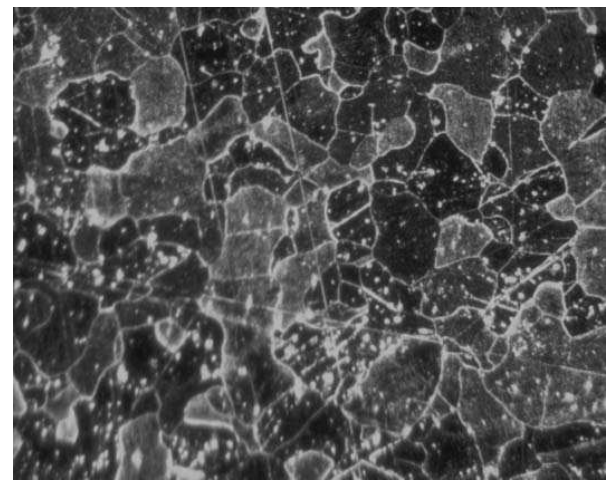

Fig. 15. A photomicrograph of the structure of Armco iron, specimen $\mathrm{P} 0$.
Table 1. Density $\rho$, Young's modulus $E$, softening value (relative to P0), amplitude-independent decrement $\delta_{i}$ for iron in different states measured at room temperature

\begin{tabular}{c|c|c|c|c|c|c}
\hline Specimen & $d, \mathrm{~mm}$ & $m, \mathrm{~g}$ & $\rho, \mathrm{g} / \mathrm{cm}^{3}$ & $\Delta \rho / \rho$ & $E, \mathrm{GPa}$ & $\delta_{i}, 10^{-5}$ \\
\hline P0 & 5 & 4.65252 & 7.8667 & 0 & 186.2 & 63.0 \\
\hline P1 & 5 & 4.68843 & 7.8654 & $1.6 \times 10^{-4}$ & 184.2 & 52.4 \\
\hline P2 & 5 & 4.63733 & 7.8533 & $1.7 \times 10^{-3}$ & 184.4 & 52.5 \\
\hline P3 & 5 & 4.63920 & 7.8522 & $1.8 \times 10^{-3}$ & 182.5 & 46.5 \\
\hline P4 & 5 & 4.50319 & 7.8522 & $1.8 \times 10^{-3}$ & 169.0 & 890.0 \\
\hline
\end{tabular}

specimen no. 2, P1 - the number of cycles $9.01 \times 10^{8}$, the load $P=161 \mathrm{MPa}$,

specimen no. 3, P2 - the number of cycles $2.10 \times 10^{9}$, the load $P=161 \mathrm{MPa}$,

specimen no. 4, P3 - the number of cycles $3.10 \times 10^{9}$, the load $P=162 \mathrm{MPa}$,

specimen no. 5, P4 - a cracked specimen due to very high cycle fatigue testing.

Initial test specimens are shown in Fig. 14a. Rods cut from these specimens have the length $l=30 \mathrm{~mm}$ and diameter $d \approx 5 \mathrm{~mm}$ so that the surface layer of the central part of the specimen remains undisturbed (Fig. 14b). Figure 15 is a photomicrograph of the structure of specimen $\mathrm{P} 0$.

Table 1 shows the mass of specimens, their diameter, density, softening value (relative to P0), Young's modu-
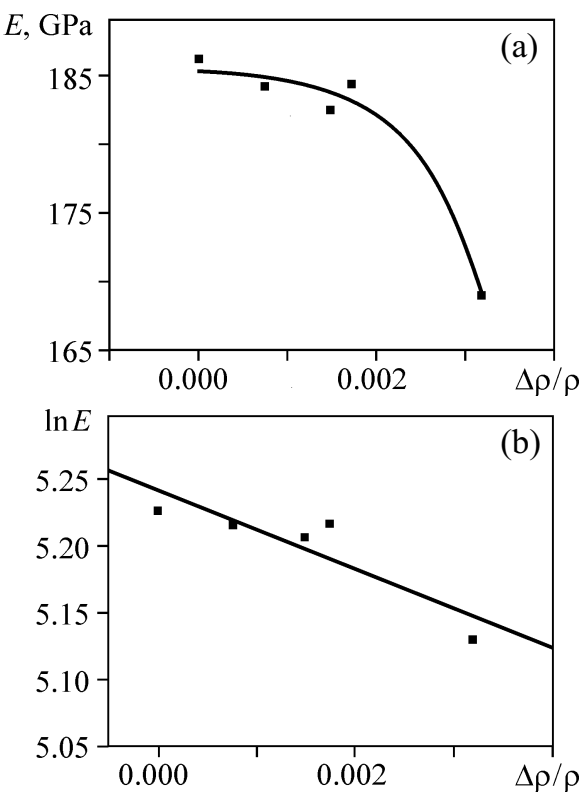

Fig. 16. Young's modulus $E$ (a) and logarithm of Young's modulus $E$ (b) versus the softening value $\Delta \rho / \rho$ due to increasing number of cycles in very high cycle fatigue testing. 
Table 2. Investigation results

\begin{tabular}{c|c|c|c|c|c|c}
\hline Material & $m, \mathrm{~g}$ & $d, \mathrm{~mm}$ & $\rho, \mathrm{g} / \mathrm{cm}^{3}$ & $\Delta \rho / \rho$ & $E, \mathrm{GPa}$ & $\delta_{i}, 10^{-5}$ \\
\hline $\mathrm{Fe}$, initial (P0) & 4.65219 & 5.00 & 7.8787 & - & 186.2 & 63.0 \\
\hline \multirow{3}{*}{$\mathrm{Fe}(\mathrm{P} 1)$} & 4.68840 & 5.00 & 7.8717 & $0.8 \times 10^{-3}$ & 184.2 & 52.4 \\
\cline { 2 - 7 } & 4.43544 & 4.90 & 7.8708 & $0.9 \times 10^{-3}$ & 182.5 & 47.1 \\
\cline { 2 - 7 } & 3.26927 & 4.22 & 7.8686 & $1.1 \times 10^{-3}$ & 180.0 & 50.9 \\
\hline \multirow{3}{*}{$\mathrm{Fe}(\mathrm{P} 2)$} & 4.63726 & 5.00 & 7.8640 & $1.7 \times 10^{-3}$ & 184.4 & 52.5 \\
\cline { 2 - 8 } & 4.45456 & 4.90 & 7.8608 & $2.1 \times 10^{-3}$ & 182.7 & 59.0 \\
\cline { 2 - 7 } $\mathrm{Fe}(\mathrm{P} 3)$ & 3.26388 & 4.22 & 7.8602 & $2.2 \times 10^{-3}$ & 181.7 & 68.4 \\
\cline { 2 - 7 } & 4.63924 & 5.00 & 7.8660 & $1.5 \times 10^{-3}$ & 182.5 & 46.5 \\
\hline \multirow{3}{*}{$\mathrm{Fe}(\mathrm{P} 4)$} & 4.42786 & 4.90 & 7.8660 & $1.5 \times 10^{-3}$ & 182.6 & 52.9 \\
\hline & 3.20559 & 4.22 & 7.8660 & $1.5 \times 10^{-3}$ & 182.4 & 69.0 \\
\hline
\end{tabular}

lus, and amplitude-independent decrement $\delta_{i}$ of iron in different states. The measurements are performed at room temperature.

As evident from the obtained data, an increasing number of cycles cause a density decrease (strain softening) in the specimens. Thus, the density value is to some extent an indicator of the defect level (degree of damage) [30] of the material. The elastic modulus $E$ is also markedly reduced with increasing number of cycles. Various factors affecting the elastic modulus $E$ were earlier analyzed [30-34]. As it is theoretically and experimentally shown, a growth in the dislocation density, cracks, and pores causes a reduction in $E$. From this viewpoint, a significant decrease of the modulus from state $\mathrm{P} 0$ to $\mathrm{P} 4$ can be explained obviously by the formation of these defects. There is also a decrease in the elastic vibration decrement $\delta_{i}$ from initial state $\mathrm{P} 0$ to $\mathrm{P} 3$ and its increase on approaching the central part of the specimen (i.e., with decreasing diameter).
Figure 16a demonstrates the dependence of Young's modulus on the softening value $\Delta \rho / \rho$ with increasing number of cycles. As shown in Fig. 16b, the porosity and Young's modulus have a natural exponential relationship.

To determine the softening value due to the crack formation after very high cycle fatigue testing specimen $\mathrm{P} 4$ is divided into three parts. The central part (gauge length) has the length $l=11 \mathrm{~mm}$, mass $m=1.62199 \mathrm{~g}$, and softening value $\Delta \rho / \rho=0.1 \%$ with respect to the end parts of the specimen. A symmetrical decrease of the central part length to $8 \mathrm{~mm}$ increases softening, which amounts to $0.2 \%$ with respect to the end parts of the specimen. The obtained results confirm the fact that the specimen fractures precisely in the investigated central part. Figure 17 is a photomicrograph of a crack in specimen P4 (central part).

The next stage of research was in reducing the diameter of cylindrical specimens P0-P3 from 5.00 to $4.22 \mathrm{~mm}$

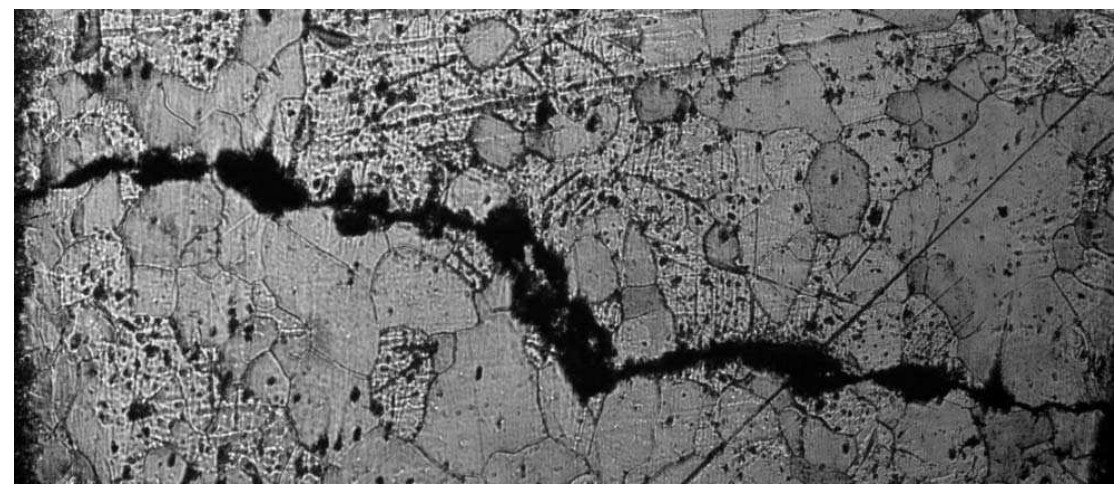

Fig. 17. A photomicrograph of a crack in specimen $\mathrm{P} 4$ at the distance of $0.15 \mathrm{~mm}$ to the surface. 

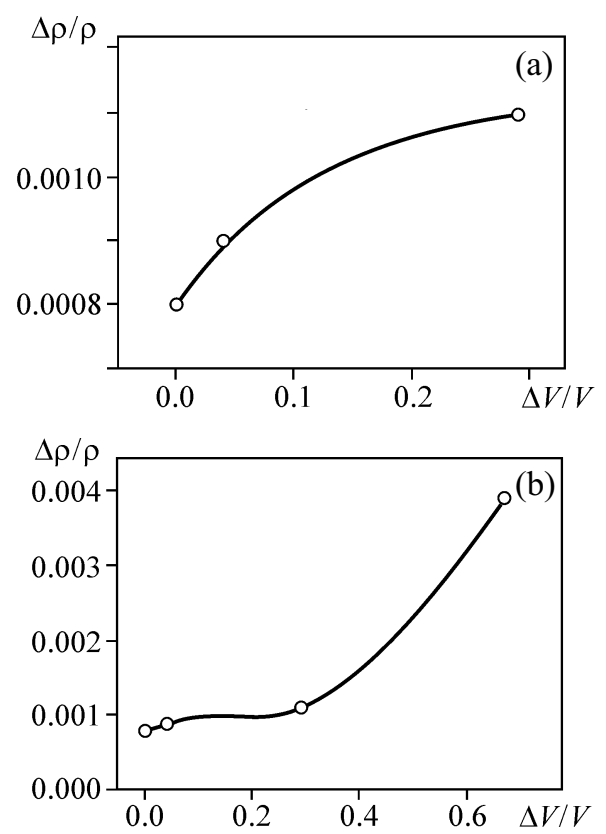

Fig. 18. Dependence of the softening value $\Delta \rho / \rho$ on the volume change $\Delta V / V$ with decreasing diameter (a) and volume of specimen P1 (b).

and determining their density and elastic-plastic characteristics after each reduction in diameter. Table 2 shows mass $m$, density $\rho$, softening value $\Delta \rho / \rho$ (relative to P0), Young's modulus, and amplitude-independent decrement $\delta_{i}$ of iron for specimens P1-P3. The measure-
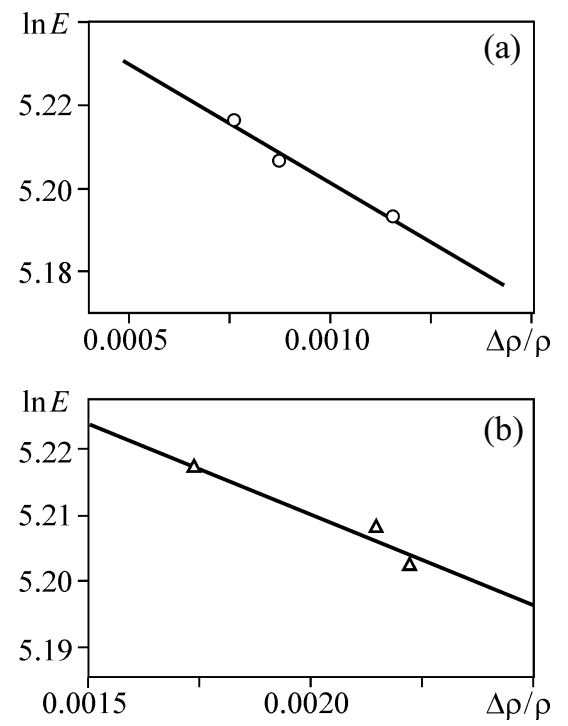

Fig. 19. The logarithm of Young's modulus $E$ versus softening $\Delta \rho / \rho$ with decreasing diameter of specimen P1 (a) and P2 (b). ments are performed at room temperature. The diameter reduction of specimen $\mathrm{P} 0$ exerted no changes in its density and elastic modulus. Optical microscopy of the specimens after each reduction of the diameter reveals no pores and cracks on the surface of specimens $\mathrm{P} 1$ and $\mathrm{P} 2$. A large crack is found on the surface of specimens P3 and $\mathrm{P} 4$ already at the initial stage at $d=5 \mathrm{~mm}$ and later with decreasing diameter.

According to the obtained data, a reduced diameter of specimens $\mathrm{P} 1$ and $\mathrm{P} 2$ results in a decrease of the density and an increase in the volume fraction of discontinuities (pores and cracks) in the specimen. Figure 18a presents these data for specimen P1 that illustrates that a decrease in the specimen volume due to a reduced diameter in this case leads to an increase in the volume fraction of softening. Figure $18 \mathrm{~b}$ plots the dependence of softening on the volume change associated also with a decrease of the specimen length. For specimen P3, an increase in softening with decreasing volume is undetected. This is probably due to the fact that pores and cracks are evenly distributed throughout the specimen section. Figure 19 exhibits the logarithm of the elastic modulus as a function of softening for specimens P1 and P2 due to a decreased diameter of the specimen. Young's modulus is seen to decrease, which is obviously due to an increase in softening of these specimens. Specimen P3 reveals insignificant changes in the elastic modulus. In general, the elastic vibration decrement $\delta_{i}$ tends to grow with decreasing diameter of the specimens. However, for specimen P1 the decrement value at $d=5 \mathrm{~mm}$ is slightly higher than those at 4.9 and $4.22 \mathrm{~mm}$.

\section{RESULTS AND DISCUSSION}

Various mechanisms of initiation and propagation of fatigue cracks in metals under high cycle and very high cycle fatigue have a variety of qualitative and quantitative fractographic properties of fracture surfaces. The developed methods of multiscale analysis enable a determination of scale-invariant characteristics (scaling parameters) of specific zones of fatigue fracture (initiation and propagation of cracks), which are related to various mechanisms and stages of defect development and fatigue crack growth.

A quantitative analysis of the surface morphology according to high-resolution profilometry made it possible to find the scale invariance of the fracture surface relief and to relate it to the self-similar nature of fatigue crack growth in the very high cycle fatigue regime. Characteristic scale $L_{\mathrm{pz}}$ and $l_{\mathrm{sc}}$, which determine boundaries of 
the zone of the correlated behavior of defects at the crack tip are related to phenomenological relations describing the fatigue crack kinetics.

The analysis of the experimental data shows that an increasing number of cycles in very high cycle fatigue testing leads to an increase in softening of Armco iron specimens, i.e. increases the damage degree associated with defects (dislocations, microscopic pores and cracks). The studies performed demonstrate that fracture occurs in the central part of the specimen. The experimental data allow us to conclude that the detected softening in specimens when tested for very high cycle fatigue is due to the formation of pores and microcracks that decrease the density of the specimen. Independent measurements of the elastic modulus, which decreases on account of the formation of pores and microcracks, confirm the formation of the fracture site in the specimen bulk.

\section{ACKNOWLEDGMENTS}

This work was supported by the Skolkovo Institute of Science and Technology (contract MRA-319) and the Russian Science Foundation (in terms of the analysis of characteristics of titanium fracture, project No. 15-1230010).

\section{REFERENCES}

1. Cowles, B.A., High Cycle Fatigue in Aircraft Gas Turbines - an Industry Perspective, Int. J. Fracture, 1996, vol. 80, pp. 147-163.

2. Shanyavsky, A.A., Simulation of Fatigue Fracture of Metals. Synergetics in Aviation, Ufa: Monografiya, 2007.

3. Peters, J.O. and Ritchie, R.O., Influence of Foreign-Object Damage on Crack Initiation and Early Crack Growth during High-Cycle Fatigue of Ti-6Al-4V, Eng. Fract. Mech., 2000, vol. 67, pp. 193-207.

4. Nicholas, T., High Cycle Fatigue. A Mechanics of Material Perspective, Elsevier, 2006.

5. Botvina, L.R., Fracture: Kinetics, Mechanisms, General Laws, Moscow: Nauka, 2008.

6. Paris, P.C., Lados, D., and Tada, H., Reflections on Identifying the Real $\Delta K_{\text {eff }}$ in the Threshold Region and Beyond, Eng. Fract. Mech., 2008, vol. 75, pp. 299-305.

7. Bathias, C. and Paris, P.C., Gigacycle Fatigue in Mechanical Practice, Marcel: Dekker Publisher Co., 2005.

8. Sakai, T., Review and Prospects for Current Studies on High Cycle Fatigue of Metallic Materials for Machine Structural Use, J. Solid Mech. Mat. Eng., 2009, vol. 3, no. 3, pp. 425-439.

9. Hong, Y., Zhao, A., Qian G., and Zhou, C., Fatigue Strength and Crack Initiation Mechanism of Very-High-
Cycle Fatigue for Low Alloy Steels, Metall. Mater. Trans. A, 2012, vol. 43, no. 8, pp. 2753-2762.

10. Mughrabi, H., Specific Features and Mechanisms of Fatigue in the Ultrahigh-Cycle Regime, Int. J. Fatigue, 2006, vol. 28, pp. 1501-1508.

11. Nicolas, T., Critical Issues in High Cycle Fatigue, Int. J. Fatigue, 1999, vol. 21, pp. 221-231.

12. Mughrabi, H. and Höppel, H.W., Cyclic Deformation and Fatigue Properties of Very Fine-Grained Metals and Alloys, Int. J. Fatigue, 2010, vol. 32, no. 9, pp. 1413-1427.

13. Mughrabi, H., Microstructural Fatigue Mechanisms: Cyclic Slip Irreversibility, Crack Initiation, Non-Linear Elastic Damage Analysis, Int. J. Fatigue, 2013, vol. 57, pp. 2-8.

14. Miller, K.J., Materials Science Perspective of Metal Fatigue Resistance, Mater. Sci. Tech., 1993, vol. 9, no. 6, pp. 453-462.

15. Hertzberg, R.W., On the Calculation of Closure-Free Fatigue Crack Propagation Data in Monolithic Metal Alloys, Mater. Sci. Eng. A, 1995, vol. 190, pp. 25-32.

16. Marines-Garcia, I., Paris, P.C., Tada, H., and Bathias, C., Fatigue Crack Growth from Small to Long Cracks in VHCF with Surface Initiations, Int. J. Fatigue, 2007, vol. 29, no. 9-11, pp. 2072-2078.

17. Barenblatt, G.I., Scaling Phenomena in Fatigue and Fracture, Int. J. Fracture, 2006, vol. 138, pp. 19-35.

18. Ritchie, R.O., Incomplete Self-Similarity and FatigueCrack Growth, Int. J. Fracture, 2005, vol. 132, pp. 197203.

19. Ciavarella, M., Paggi, M., and Carpinteri, A., One, No One, and One Hundred Thousand Crack Propagation Laws: A Generalized Barenblatt and Botvina Dimensional Analysis Approach to Fatigue Crack Growth, J. Mech. Phys. Solids, 2008, vol. 56, pp. 3416-3432.

20. Oborin, V.A., Bannikov, M.V., Naimark, O.B., and PalinLuc, T., Scaling Invariance of Fatigue Crack Growth in Gigacycle Loading Regime, Tech. Phys. Lett., 2010, vol. 36, no. 11, pp. 1061-1063.

21. Bouchaud, E., Scaling Properties of Cracks, J. Phys. Condens. Matter, 1997, vol. 9, pp. 4319-4344.

22. Naimark, O.B., Bayandin, Yu.V., Leontiev, V.A., Panteleev, I.A., and Plekhov, O.A., Structural-Scaling Transitions and Thermodynamic and Kinetic Effects in Submicro(Nano-)crystalline Bulk Materials, Phys. Mesomech., 2009, 12, no. 5-6, 239-248.

23. Froustey, C., Naimark, O., Bannikov, M., and Oborin, V., Microstructure Scaling Properties and Fatigue Resistance of Pre-strained Aluminium Alloys, Eur. J. Mech. A. Solids, 2010, vol. 29, pp. 1008-1014.

24. Oborin, V., Bannikov, M., Naimark, O., Froustey, C., Long-Range-Correlation Large-Scale Interactions in Ensembles of Defects: Estimating Reliability of Aluminium Alloys under Dynamic Cycling and Fatigue Loading, Tech . Phys. Lett., 2011, vol. 37, no. 3, pp. 241-243.

25. Bannikov, M.V., Naimark, O. B., and Oborin, V.A., Experimental Investigation of Crack Initiation and Propagation 
in High- and Gigacycle Fatigue in Titanium Alloys by Study of Morphology of Fracture, Fratt. Integr. Strutt., 2016, vol. 35 , pp. 50-56.

26. Sornette, D., Critical Phenomena in Natural Sciences, Berlin: Springer, 2006.

27. Abaimov, S.G., Statistical Physics of Non-Thermal Phase Transitions (From Foundations to Applications), Series in Synergetics, Cham: Springer, 2015.

28. Bannikov, M., Oborin, V., and Naimark, O., Experimental Study of Crack Initiation and Propagation in High- and Gigacycle Fatigue in Titanium Alloys, AIP Conf. Proc., 2014, vol. 1623, pp. 55-58.

29. Nikanorov, S.P. and Kardashev, B.K., Elasticity and Dislocation Inelasticity of Crystals, Moscow: Nauka, 1985.

30. Betekhtin, V.I., Kolobov, Yu.R., Narykova, M.V., Kardashev, B.K., Golosov, E.V., and Kadomtsev, A.G., Mechanical Properties, Density, and Defect Structure Submicrocrystalline Titanium VT1-0 Obtained after Severe Plastic Deformation at Screw and Longitudinal Rolling, Zhur. Tekh. Fiz., 2011, vol. 81, no. 11, pp. 58-63.
31. Betekhtin, V.I., Sklenicka, V., Saxl, I., Kardashev, B.K., Kadomtsev, A.G., and Narykova, M.V., Effect of the Number of Passes in Equal Channel Angular Pressing on the Elastic-Plastic Properties, Durability, and Defect Structure of the Alloy Al + 0.2 wt. \% Sc, Phys. Solid State, 2010, vol. 52, no. 8, pp. 1629-1636.

32. Betekhtin, V.I., Kadomtsev, A.G., and Kardashev, B.K., Elasticity and Anelasticity of Microcrystalline Aluminum Samples Having Various Deformation and Thermal Histories, Phys. Solid State, 2006, vol. 48, no. 8, pp. 15061512.

33. Betekhtin, V.I., Kardashev, B.K., and Narykova, M.V., Elastoplastic Properties and Defect Structure of Ultramicrocrystalline Aluminum and Its Alloys, Nauch. Tekh. Vedom. SPbGPU, 2010, vol. 4, pp. 104-113.

34. Plekhov, O., Prokhorov, A., Naimark, O., Narykova, M., Kadomtsev, A., and Betechtin, V., The Study of Dilatation Evolution and Elastic Properties Degradation in Metals under Deformation in Gigacycle Fatigue Regime, Eng. Fract. Mech., 2016, vol. 167, pp. 273-283. 